\title{
Metaphor in Eco Architecture
}

\author{
Author: Klodjan Xhexhi ${ }^{1}$ \\ Affiliation: Polytechnic University of Tirana, Albania; Faculty of Architecture and Urbanism ${ }^{1}$ \\ E-mail:klodjanxhexhi@yahoo.com
}

DOI $10.26821 /$ IJSHRE.8.8.2020.8804>

\begin{abstract}
Metaphor plays a central role in changing the architectural process. In order to better appreciate the nature of architectural creativity, generating more positive forms and volumes is required. Exists many conclusions which demonstrate that metaphors plays an important role shaping the design creativity.
\end{abstract}

The aim of this paper is about understanding the exact role of the metaphor in architecture design from the concept of Aristotle to nowadays. Essentially it is the process by which most of the ideas come into being. Metaphors structure our understanding and perceptions. They make our thoughts more interesting and more vivid.

There are similar distinct uses of metaphor in architectural criticism, which is often heavily reliant on metaphor both as a form of expression and a tool of analysis. There is a dimension of meanings attached to the various uses of metaphor, ranging from the ornamental view at one hand to the rational view at the other [1].

Metaphors role in the ecological design is essential and necessary. Architects use a variety of methods and techniques to enrich the architectural language. This process is accomplished with the infiltration of metaphors as a literary figure. By adopting the models of nature, there is a chance to work more sustainably and produce more sustainable products. Is this the paradigm shift we have been looking for? Maybe biomimicry and nature could be super metaphors in order to develop sustainable design.

This paper should take in consideration also the metaphor as a tool implemented into design reflecting either positive or negative reactions. This theory should be explained by concrete examples. The working metaphor in the design process is another important issue to be judged.

The aim of this paper is to demonstrate that architectural metaphors corporate in coherent ways with architectonic language shaping its functionality. Metaphor helps to perceive things from a different perspective that is new to us, changing and bringing new ideas. Architectural metaphors can be found everywhere also in the Albanian case. It is very evident how metaphor stretches architectural functionality.

Keywords: building metaphors, dynametaphor, biometaphor.

\section{INTRODUCTION}

The metaphor in a word lives when the word brings to mind more than a single reference and the several references are seen to have something in common. Instead of re-using known design schemas and familiar solutions, the implementation of metaphors in design practice can contribute to creative allow the designer to think unconventionally and encourage the application thinking and thereby to more innovative products. [2].

Metaphor, has its origin from the Greek meaning "to carry across" is the word or phrase denoting the use of one kind of idea or object in place of another word or phrase for the purpose of suggesting a likeness between the two [3].

There are many uses of metaphor but the most common derive from Aristotle: "Metaphors consist in giving a thing a name that belongs to something else". Aristotle also says: "Metaphors moreover give style, clearness, charm, and distinction as nothing else can [1].

Metaphor is often considered as something that belongs in poetry that is more concerned with novel or interesting uses of words than with accepted, everyday practice. Some linguists and other language researchers have a different perspective, however. According to George Lakoff and Mark Johnson [4]; [5]; [6], metaphor may, in fact, be far more central to human language, indeed to our very thought. Lakoff and Johnson show how 
Volume 8 Issue 8 August 2020

metaphor is pervasive in everyday life, and how it is more than just a matter of language; it may structure our entire conceptual system.

Contemporary theories have defined metaphors as a structuring of our cognitive system [4]; [7]. Metaphors affect the way we perceive the world, categorize experiences, and organize our thoughts. These devices have a fundamental role, as they not only guide reasoning but also enhance innovative thinking. The employment of metaphors by architects is well documented in literature through a vast number of examples. Nevertheless, not many empirical investigations have verified the contribution of metaphors to design. In a recent study, Casakin [8] found that metaphors help to identify and capture design concepts, as well as define goals and requirements. In another research, the aid provided by metaphors to develop unconventional solutions was seen to be more fruitful in the initial stages of the design process, known as conceptual design. Metaphor use in the final stages of the design process is more complex and therefore demands more expertise [9].

Apart from knowledge and expertise, design problems require creativity. To enhance their creativity, designers use different kinds of principles, tools, and heuristics, such as metaphors [10]. Despite its significance, no empirical/studies have been conducted in order to study the contribution of metaphors to design creativity.

The link of metaphor to sustainability and bio mimicry is also strong. Biomimicry (from bios, meaning life, and mimesis, meaning to imitate) is a design discipline that studies nature's best ideas and then imitates these designs and processes to solve human problems. Studying a leaf to invent a better solar cell is an example of this "innovation inspired by nature." The core idea is that nature, imaginative by necessity, has already solved many of the problems we are grappling with. Animals, plants, and microbes are the consummate engineers. They have found what works, what is appropriate, and most important, what lasts here on Earth. This is the real news of bio mimicry: After 3.8 billion years of research and development, failures are fossils, and what surrounds us is the secret to survival [11].

\section{HOW THE METAPHORE WORKS?}

The main concern by integrating the metaphor is communication of it with the architectural process. The metaphor is inserted in various stages of knowledge, starting from the concept and in the group design decisions. In order to minimize these difficulties an original tool called the "Evoked Metaphor" (EM) is injected.

This tool, created based on Kansei (Kansei is a Japanese term related to the human mental sense of subjectivity, and often associated to emotion, affect, or subjectivity). Information considerations, allows the design group to share knowledge and to communicate thanks to a metaphor analog to the design project itself. The "Evoked Metaphor" allows group members to converse and to exchange knowledge thanks to a common ground [12]. The most important characteristic of the "Evoked Metaphor" is that everybody can understand it intuitively. The "Evoked Metaphor" is not static throughout the project. It can evolve, integrating new factors, created elements, deeper reflections from the group member's, and so on. Its evolution means its maturity and its increasing relevancy.

The inclusion of the "Evoked Metaphor" in the design process modifies it. The first part of the process (design analysis) does not change, but its output is often differently. Instead of passing directly from the design analysis to the design synthesis, a shift to a metaphorical level is required to build the EM (Evoked Metaphor).

The "Evoked Metaphor" works in three main levels of the design process: in the conceptual level, at the level of development (reality level), and also in the technical level of the design process. This permanence has a few but strong consequences on the process [13].

\section{METAPHORE AS A CREATIVITY PROCESS}

Metaphors help organize design thinking and treat ill-defined design problems. Metaphorical reasoning is an iterative process through which designers gradually increase their knowledge of a design situation. The use of metaphors aids in structuring design problems. Thus, when solving design problems, it is difficult to predict what a solution will look like. Reflecting on a design situation was seen to have a strong effect on the 
Volume 8 Issue 8 August 2020

perception, analysis, and framing of a problem. These are important reasons to believe that metaphors stimulate design creativity.

There are many examples that illustrate the role of metaphors in design practice. For instance, the dictum 'form follows function' - meaning that the external appearance of a building comes as a result of the building's internal use, together with the other dictum "form and function are one", influenced a whole generation of architects identified with the Modern Movement [14]. An important case of the use of metaphors in practice is the design of the prairie houses by the famous architect Frank Lloyd Wright, characterized by additive simple volumes interlocking with relative freedom to each other in accordance to functional needs [15]. "Form follows function" was put into practice by Wright in the design of a large number of works, such as the Robie House at Chicago, the Fricke House etc.

Another important architect that get used of the metaphors is Mies van der Rohe. In the early 20th century, the seminal design philosophies of American architect Louis Sullivan, "form follows function", and Austrian architect Adolf Loos, "ornament is crime", gave rise to one of the most potent form finding methods of the Modernist movement functionalism. Mies Van Der Rohe's famous dictum "less is more", followed, elevating functionalism to a position of primacy. Generations of designers embraced its tyranny, designing forms that were slave to functional. His memorable metaphor "less is more" makes reference to the engineering idea of reducing architectural design to its minimal and basic nature. The application of metaphor in his work was achieved by means of reducing spatial dimensions to the minimum habitable, eliminating unnecessary materials and decoration, as well as designing simple but not simplistic details [16].

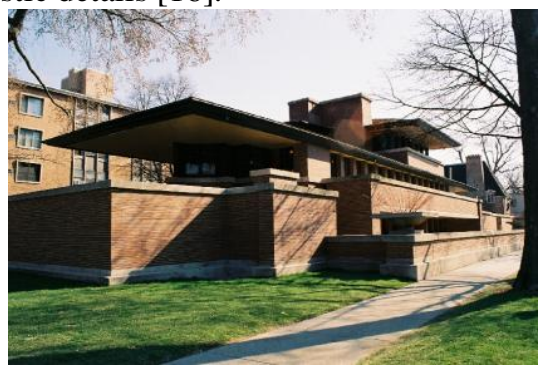

Fig 1: Robbie House at Chicago (Frank Lloyd Right)

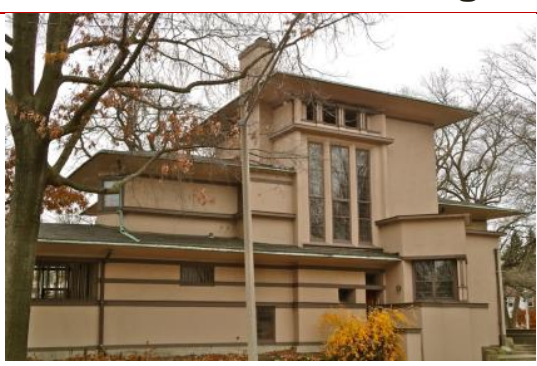

Fig 2: William Fricke Home (Frank Lloyd Wright)

Fig 3: Lake Shore Drive Apartments (Mies Van De Rohe)

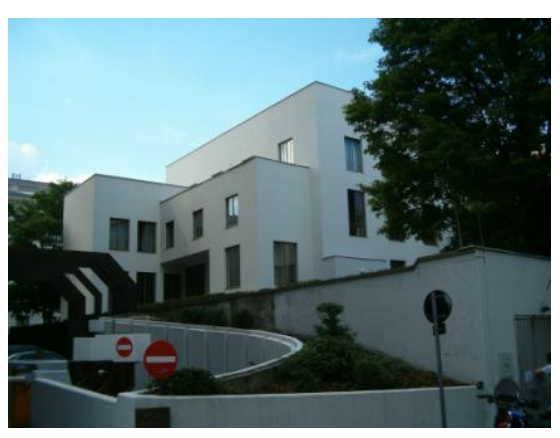

Fig 4: Wittgenstein Haus, Vienna, Austria (Adolf Loos)

"Yes Is More" is the motto of the Danish architectural firm Bjarke Ingles Group (BIG), which follows an evolving series of precedents in mottoes from the last century. Modernism was about the paring of ornament and reducing architecture to its simplest and basic austerity. This was seen as progressive as it was a break from past historical precedents which had dominated architecture for centuries. Since less ornament is progressive, and progress is good (more being metaphorical for good), the metaphor "Less Is More" arises. So Venturi's "Less Is a Bore" counters this Modernistic rationalism. "More Is More" is relaying the honesty of architecture to architecture itself and the designer being conscious of this ontological aspect of design. Rather than 
Volume 8 Issue 8 August 2020

allowing less to represent more, more should represent itself. So the more and more we build, the more and more entropy should follow, likewise equilibrium and organization. Progress is progress, and nothing less. Obama's declaration "Yes We Can" embrace the optimism of the new era, and is, likewise, metaphorical to progress [17].

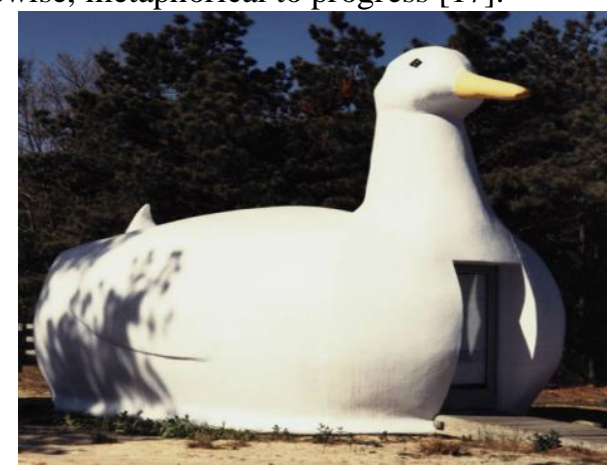

Fig 5: Ventur's duck

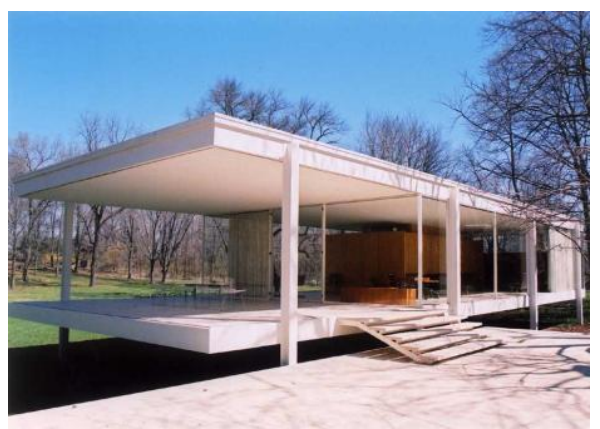

Fig 6: Farnsworth House, Mies van der Rohe

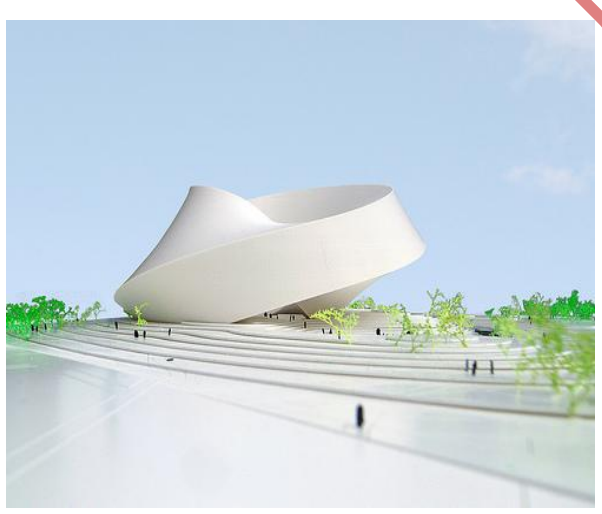

Fig 7: ANL Astana National Library Competition, Astana, Kazakhstan BIG

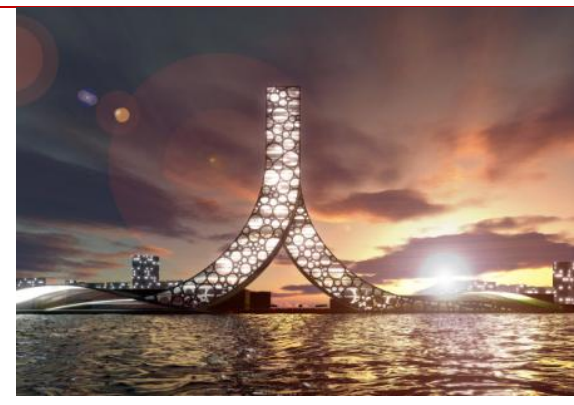

Fig 8: Peoples building; Shanghai, China (20042005 and ongoing) BIG

\section{METAPHORS AND BIO- MIMICRY}

Nature is abundant and offers an incredible number of designs to learn from. Architects, engineers and designers can take advantage of that wealth of knowledge to aid in design by working with biologists, natural historians and others with more readily accessible information on the natural world. The design "leads" that nature offers are unparalleled and often fulfill sustainable design criteria. By consciously consulting nature, we reestablish the connection with nature that we have long since parted with. We begin learning from her again and are able to draw inspiration from "life" to help guide our designs. The possibilities are as endless as nature is diverse. Biomimics around the world are looking to nature for clues on how to capture energy from the sun, how to heat and cool buildings, manufacture materials, and even design communities.

By looking to nature for design inspiration, our designs can become conducive to life. Start a conversation with nature yourself. Ask her what she would do in a particular situation. More importantly, listen to how she replies. You may be surprised by what you learn. Our forests, oceans and air will again be recognized as life givers. We will again recognize ourselves as part of something greater. We will begin to recognize ourselves as part of nature. We will fit in again [18].

As the time goes by architects should find other solutions to represent better the future. The metaphor shapes the system, by identifying key objects and suggesting aspects of their interfaces. It supports the static and dynamic object models of the system. The architecture of the future will draw 
Volume 8 Issue 8 August 2020

inspiration, not from the machines of the 20th century, but from the beautiful flowers that grow in the landscape that surrounds them. Architecture has often been described using metaphors, drawing comparisons to things in the world that evoke similar emotional responses and can quickly sum up the intent of the architects' expression. In contrast to "machines for living in," Goethe once said that "architecture is music etched in stone."

\section{DESIGN LOOKING TO BIOLOGY}

The approach where designers look to the living world for solutions requires designers to identify problems and biologists to then match these to organisms that have solved similar issues. This approach is effectively led by designers identifying initial goals and parameters for the design.

An example of such an approach is DaimlerChrysler's prototype Bionic Car. In looking to create a large volume, small wheel base car, the design for the car was based on the boxfish (ostracion meleagris), a surprisingly aerodynamic fish given its box like shape. The chassis and structure of the car are also biomimetic, having been designed using a computer modelling method based upon how trees are able to grow in a way that minimises stress concentrations. The resulting structure looks almost skeletal, as material is allocated only to the places where it is most needed [20].

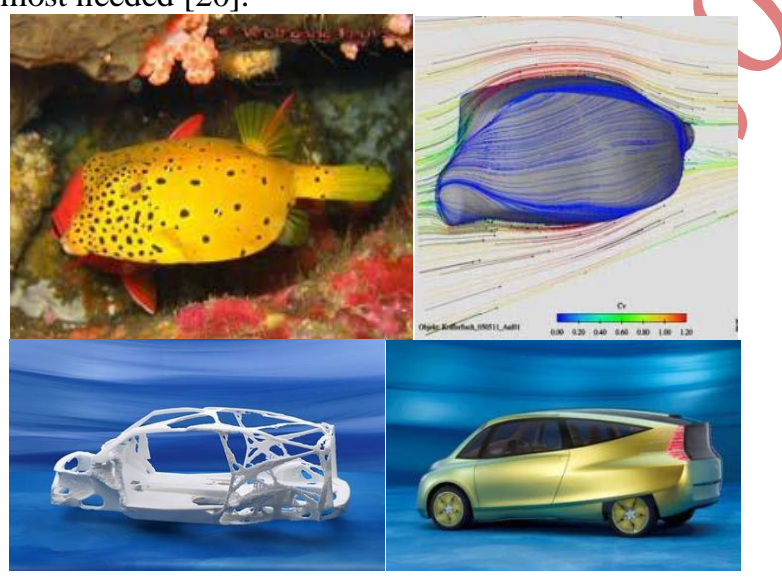

Fig 9: DaimlerCrysler bionic car inspired by the box fish and tree growth patterns.

The Bionic Car illustrates the point. It is more efficient in terms of fuel use because the body is more aerodynamic due to the mimicking of the box fish. It is also more materials efficient due to the mimicking of tree growth patterns to identify the minimum amount of material need in the structure of the car. The car itself is however not a new approach to transport. Instead, small improvements have been made to existing technology without a re-
What is interesting with architecture, is that when the metaphor changes, new sets of rules of emerge that can guide the design process [19].

Many technologies are currently in use or being developed relying in bio mimicry and in nature and will contribute to improve the living habitat. Metaphor is part of it.

examination of the idea of the car itself as an answer to personal transport.

Another example is the scientific analysis of the lotus flower emerging clean from swampy waters, which led to many design innovations as detailed by Baumeister (2007a), including Sto's Lotusan paint which enables buildings to be self-cleaning.

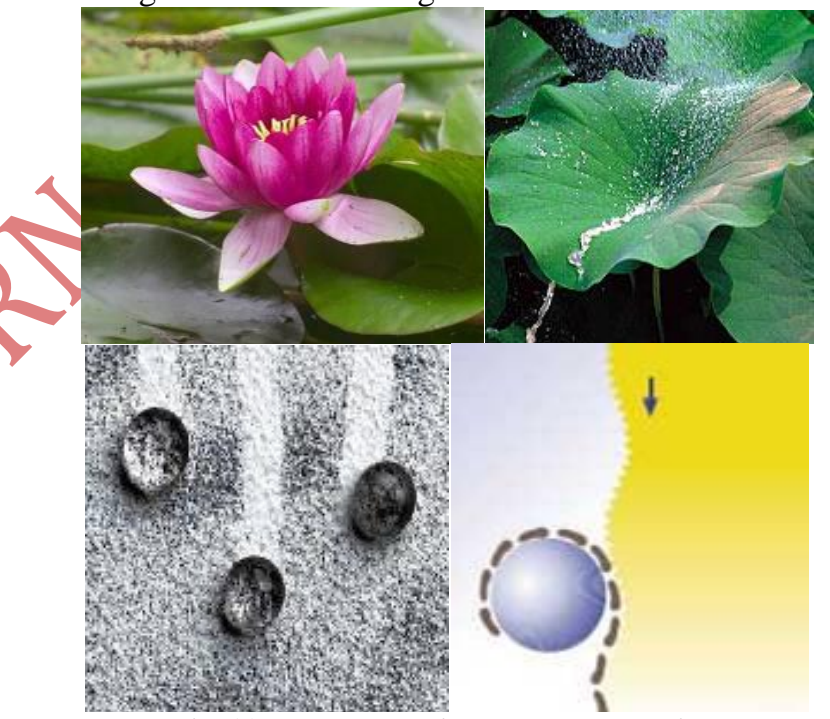

Fig 10: Lotus Inspired Lotusan Paint.

An example is the mimicking of the Namibian desert beetle, stenocara [21]. The beetle lives in a desert with negligible rainfall. It is able to capture moisture however from the swift moving fog that moves over the desert by tilting its body into the wind. Droplets form on the alternating hydrophilic - hydrophobic rough surface of the beetle's back and wings and roll down into its mouth [22]. Matthew Parkes of KSS Architects demonstrates process biomimicry at the organism level inspired by the beetle, with his proposed fog-catcher design for the Hydrological Center for the University of Namibia [23] discuss a more specific material biomimicry at the organism level, where the surface of the beetle has been studied and mimicked to be used for other potential applications such as to clear fog from airport runways and improve dehumidification equipment for example. 
Volume 8 Issue 8 August 2020

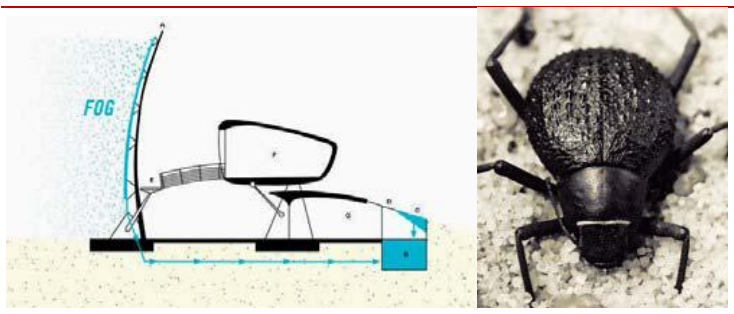

Fig 11: Matthew Parkes' Hydrological Center for the University of Namibia and the stenocara beetle.

Nicholas Grimshaw \& Partners' design for the Waterloo International Terminal demonstrates an example of form and process biomimicry at the organism level. The terminal needed to be able to respond to changes in air pressure as trains enter and depart the terminal. The glass panel fixings that make up the structure mimic the flexible scale arrangement of the Pangolin so they are able to move in response to the imposed air pressure forces [24].
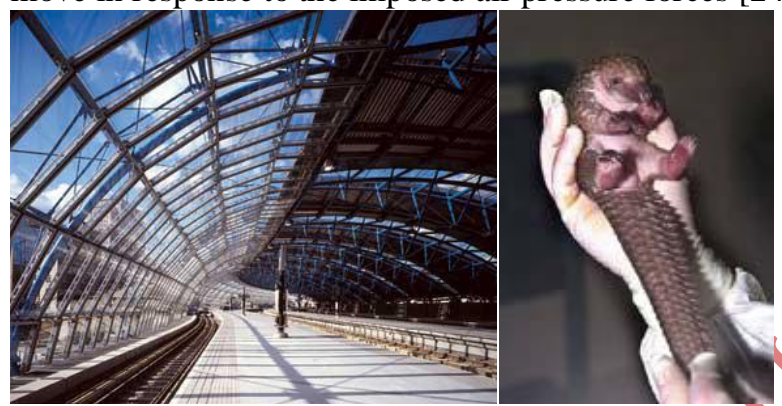

Fig 12: Nicholas Grimshaw \& Partners' Waterloo. International Terminal and the pangolin.

The example of the North American beaver (castor canadensis) demonstrates how through its altering of the landscape, wetlands are created and nutrient retention and plant and animal diversity is increased, helping in part to make the ecosystem more resilient to disturbance [25].

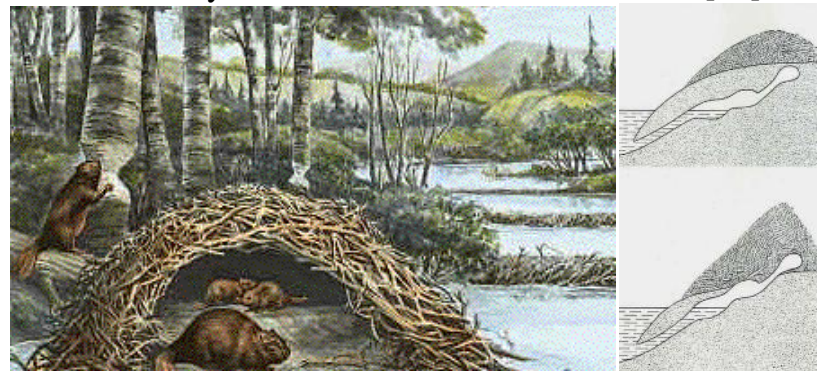

Fig 13: The North American Beaver

In behavior level biomimicry, it is not the organism itself that is mimicked, but its behavior. It may be possible to mimic the relationships between organisms or species in a similar way. An architectural example of process and function biomimicry at the behavior level is demonstrated by Mick Pearce's Eastgate Building in Harare, Zimbabwe and the $\mathrm{CH} 2$ Building in Melbourne, Australia. Both buildings are based in part on techniques of passive ventilation and temperature regulation observed in termite mounds, in order to create a thermally stable interior environment. Water which is mined (and cleaned) from the sewers beneath the $\mathrm{CH} 2$ Building is used in a similar manner to how certain termite species will use the proximity of aquifer water as an evaporative cooling mechanism.
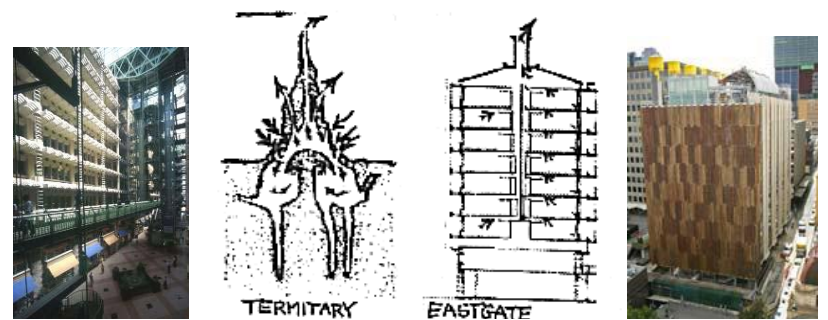

Fig 14: Eastgate Building in Harare, Zimbabwe and CH2 Building in Melbourne, Australia

A further advantage of an ecosystem based biomimetic design approach is that it is applicable to a range of temporal and spatial scales and can serve as an initial benchmark or goal for what constitutes truly sustainable or even regenerative design for a specific place as demonstrated by the Lloyd Crossing Project.

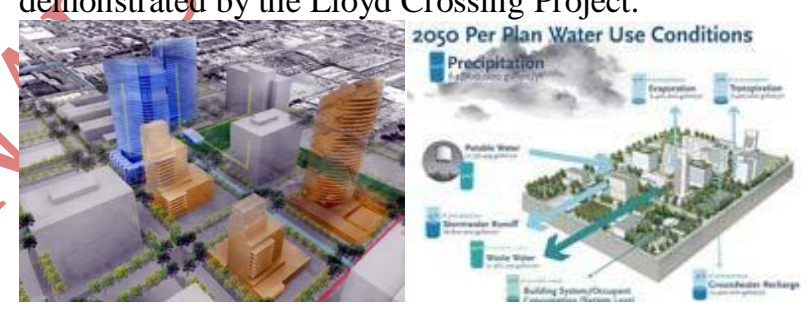

Fig 15: Lloyd Crossing Project, Portland, USA

The most important advantage of such an approach to biomimetic design however may be the potential positive effects on overall environmental performance. Ecosystem based biomimicry can operate at both a metaphoric level and at a practical functional level. At a metaphoric level, general ecosystem principles (based on how most ecosystems work) are able to be applied by designers with little specific ecological knowledge. An example of it is the Dog building New Zeland.

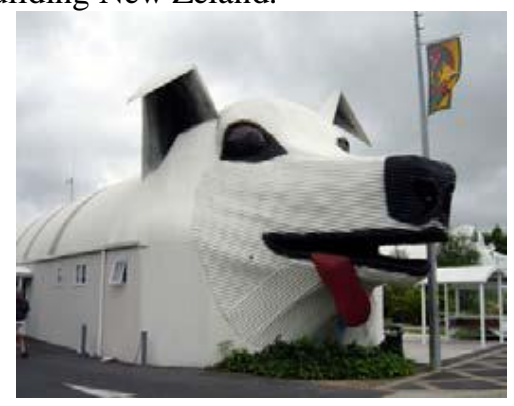

Fig 16: Dog Building, Tirau, New Zealand

The sings of the working metaphor are very visible also in Tirana, Albania with a typical building. Proximity to the airport has called and has made the integration of the 
Volume 8 Issue 8 August 2020

metaphor possible, as a participant in architectural decision-making. The resemblance to the flying object (airplane) which appears to have parked on the ground is evident. There are two elements which are taken into consideration: the treatment of architectural plastic and the functional aspect of the building. These two elements cooperate together making the metaphor more evident and vivid. In this case the role of metaphor is shaping and imposed on architectural language and function.

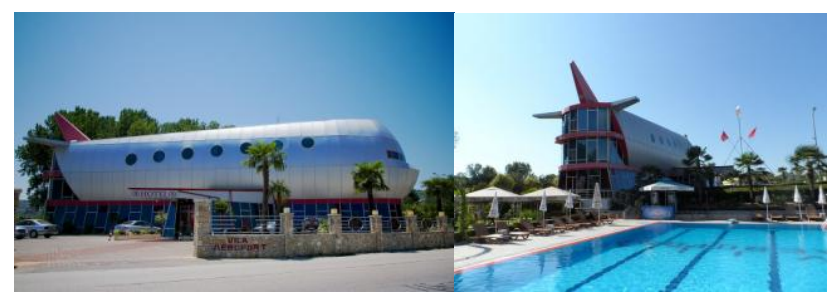

Fig 17: Vila airport hotel, Tirana, Albania

Another important example of the Albanian case is Taiwan center in Tirana. The shape resemble so much to a giant octopus adapting and generating from it a wellknown multifunctional center, right in the center of the capital of Albania, Tirana. This allegory is further reinforced by the presence of the water basin in front of the building. The metaphor once again is shaping the architectural form, inspiring from the nature itself.

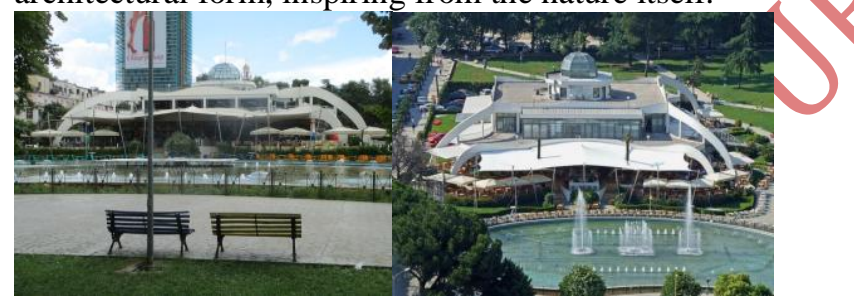

Fig 18: Taiwan center in Tirana

\section{CONCLUSIONS}

Metaphors are cognitive strategies of the design thinking. The scope of metaphor first of all is to support the design of the innovative products and to improve also the design practice. Metaphors develop strong abilities in conceptual thinking and stimulate creativity in design thinking. They are powerful tools of communication.

Man has an intimate relation between him and his building. Referring to him metaphorically speaking, he has three skins: his own his clothing and his dwelling. The metaphorical nature of a building as a skin is clearly noted. People also relate to buildings with feeling and emotion, get to like or dislike them and tend to ultimately treat buildings. We must compare buildings as part of human body, referring to their fronts, backs, faces, silhouettes, tops, middles and bases. Buildings like people have shape, personality and individual features. The metaphor support and shape the dynamic and static models of the system by identifying the main key objects.
The link of metaphor to sustainability and bio mimicry is becoming stronger and stronger. Bio mimicry follows life's principles and metaphor is a follower of it. The value of bio mimicry has not gone unnoticed. Its relationship with organic terms is also important.

The term "organic" is chosen not only because of the technologies of the most important developments in the field, but also for the inspiration provided by million shapes in the nature. In the nature exists many forms of different varieties. They can be transformable and flexible in the same time; they can be adaptable and evolvable. Our future will be flourishing with thousand of shapes as flexible and transformable as organic life itself. Bio mimicry is not simply using natural organisms for our benefit, but rather applying methods found in natural systems to optimize existing processes and enhance future designs.

Metaphors can be found not just in exterior architectonic volumes and forms but also at the level of architectonic details being part of the whole architectural concept.

The Albanian case is represented by two typical building where the strong metaphorical influence is imposing on the function and architectural language.

\section{REFERENCES}

[1]. Abel. Ch. "Architecture and identity, second edition, responses to cultural and technological change", part two p 97-113. Architectural Press. 2000

[2]. Casakin, H. P. (2007). Factors of metaphors in design problem-solving: Implications for design creativity. International Journal of Design, 1(2), 21-33.

[3]. Webers new twentieth century dictionary (1959) Cleveland the world published company.

[4]. Lakoff, G., and Johnson, M. (1980). Metaphors we live by. Chicago and London: University of Chicago Press.

[5]. Lakoff, G. and Johnson, M. (1999). Philosophy in the flesh: The embodied mind and its challenge to western thought. New York: Basic Books.

[6]. O'Keefe, J. (1990). A computational theory of the hippocampal cognitive map. In O. P. Ottersen.

[7]. Lakoff, G. (1987). Women, fire and dangerous things: What categories reveal about the mind. J. Strom-mathisen (eds.), Understanding the brain through the hippocampus, 287-300. Progress in brain research, vol. 83. Amsterdam: Elsevier. Chicago and London: University of Chicago Press.

[8]. Casakin, H. P. (2004). Metaphors in the design studio: Implications for education. In P. Lloyd, N. Roozenburg, C. McMahon, \& L. Brodhurst (Eds.), 
Volume 8 Issue 8 August 2020

Proceedings of 2nd International Engineering and Product Design.

[9]. Casakin, H. P. (2006). Assessing the use of metaphors in the design process. Environment and Planning B: Planning and Design, 33(2), 253 -268.

[10]. Casakin, H. P., \& Kreitler, S. (2005a). The determinants of creativity: Flexibility in design. In P. Rodgers, L. Brodhurst, \& D. Hepburn (Eds.), Proceedings of the 3rd Engineering \& Product Design Education International Conference (pp. 303307). London: Taylor \& Francis.

[11]. Biomimicry Institute (2008). "What is Biomimicry?" Retrieved 12 June 2008 from Biomimicry Institute. Website: http://biomimicryinstitute.org/about-us/what-isbiomimicry.html date 04.04.11 h 12.30

[12]. Lévy P. and Yamanaka T, Interdisciplinary workgroup methodology based on Intuition Application to a communication tool design based on Kansei information approach, Kansei Engineering International Journal, Vol.5, No.4, pp.31-40, 2006

[13]. Lévy P. Interdisciplinary Design for the Cyberspace by an approach in Kansei Information Methodology and Workgroup Communication Tool Design approach in Kansei, Doctoral thesis of the University 2006.

[14]. Colquhoun, A. (2002). Modern architecture. Oxford: University Press.

[15]. Casakin, H. P. (2007). Factors of metaphors in design problem-solving: Implications for design creativity. International Journal of Design, 1(2), 2335 .

(6) (PDF) Metaphors in Design Problem-Solving: Implications for Creativity. Available from: https://www.researchgate.net/publication/256503979

_Metaphors_in_Design_Problem-

Solving_Implications_for_Creativity [accessed Aug 17 2020].

[16]. Carter, P. (1999). Mies van der Rohe at work. Hong Kong: Phaidon

[17]. http://chronoperceptions.blogspot.com/2010/12/yes-is-morechanging-metaphor-for.html date 31.03 .11 h 24.30
[18]. http://biomimicry.typepad.com/bioinspi re/files/BioInspire.7-07.17.03.pdf date.18.04.11 h 12.45 .

[19]. Biomimicry Institute (2011). "What could nature teach us?" Retrieved 06 April 2011 from Biomimicry Institute. Website: http://biomimicryinstitute.case studies.$h t m l$ date 06.04.11 h 12.30

[20]. Vincent, J. F. V., Bogatyrev, O. A., Bogatyrev, N. R., Bowyer, A. \& Pahl, A.-K. (2006) Biomimetics - its practice and theory. Journal of the Royal Society Interface, April 2006 ,

[21]. Garrod, R. P., Harris, L. G., Schofield, W. C. E., McGettrick, J., Ward, L. J., Teare, D. O. H. \& Badyal, J. P. S. (2007) Mimicking a Stenocara Beetle's Back for Microcondensation Using Plasmachemical Patterned Superhydrophobic- Superhydrophilic Surfaces. Langmuir, 23, 689-693.

[22].

Parker, A. R. \& Lawrence, C. R. (2001) Water capture by a desert beetle. Nature, 414, 33.

[23]. Killeen, M. (2002) Water Web. Metropolis Magazine, May.

[24]. Aldersey-Williams, H. (2003) Zoomorphic - New Animal Architecture, London, Laurence King Publishing.

[25]. Rosemond, A. D. \& Anderson, C. B. (2003) Engineering Role Models: Do NonHuman Species have the Answers? Ecological Engineering, 20, 379-387. 